\title{
Penile implants: a look into the future
}

\author{
Katherine M. Rodriguez ${ }^{1}$, Taylor P. Kohn ${ }^{1}$, Anthony B. Davis ${ }^{2}$, Tariq S. Hakky ${ }^{2}$ \\ ${ }^{1}$ Baylor College of Medicine, Houston, TX, USA; ${ }^{2}$ Advanced Urology, Snellville, GA, USA \\ Contributions: (I) Conception and design: All authors; (II) Administrative support: AB Davis, TS Hakky; (III) Provision of study material or patients: \\ All authors; (IV) Collection and assembly of data: All authors; (V) Data analysis and interpretation: All authors; (VI) Manuscript writing: All authors; \\ (VII) Final approval of manuscript: All authors. \\ Correspondence to: Tariq S. Hakky, MD. Advanced Urology, 1557 Janmar Rd, Snellville, GA 30078, USA. Email: tariq7@gmail.com.
}

\begin{abstract}
Inflatable penile prosthesis (IPP) has been around since the 1970's as a durable and one-time cure for erectile dysfunction (ED). For the past 40 years, many changes have been made to make the device better and currently IPP boasts a high percentage of long-term patient satisfaction. The next paradigm shift in IPP treatment for ED is upon us. Funding for ED related medications and devices has been a hot topic in health policy over the last 10 years. This suggests that the device must improve and patient advocacy and education must increase for IPP to remain as a viable solution for ED. In this paper, we conduct a literature search for innovations in IPP and argue that IPP must constantly improve to compete with oral, injectable, shockwave, and potentially gene therapies.
\end{abstract}

Keywords: Erectile dysfunction (ED); penile prosthesis; trends; prostheses and implants

Submitted Mar 10, 2017. Accepted for publication May 05, 2017.

doi: $10.21037 /$ tau.2017.05.28

View this article at: http://dx.doi.org/10.21037/tau.2017.05.28

\section{Introduction}

The inflatable penile prosthesis (IPP) is now seen as the gold standard in the treatment of ED refractory to medical therapy, and boasts satisfaction rates of greater than $90 \%$. A 1994 survey, the Massachusetts Male Aging Study (MMAS), found that erectile dysfunction (ED), was increasingly common in men over 40 years old. The study estimated that $40 \%$ of these men experienced symptoms of ED including loss of libido, lower satisfaction with sex, or impaired ejaculation (1). While there are many treatment options for ED, IPP remains a good option for men who fail oral and injectable therapy, as well as men with penile deformity.

The IPP was first invented in 1973 by Dr. F. Brantley Scott at Baylor College of Medicine. It was a welcomed improvement from primitive prosthetics and semi-rigid devices as it offered the patient a more natural detumescent state. The IPP has been used to treat the many etiologies of ED including vascular, neurologic and psychosomatic. Since its inception both the procedure and IPP devices have evolved (2-4). While IPP remains a good option with high satisfaction and low complication rates, there are some aspects about the device that can improve. In today's landscape of rapidly emerging medical technology, and a thriving ED market, all treatment modalities must continue to improve. In this review, we summarize the modern advances of the IPP and potential future advancements that are warranted to continue this paradigm.

\section{The advent of modern IPP}

The first known penile prosthetic procedures were performed in the 16th century when Ambroise Pare fashioned a penis out of wood to allow micturition in traumatic penile amputation patient [3]. Since then, there have been multiple attempts at penile prosthesis that eventually led to what we know today as IPP. In the modern era, the first known attempt at penile prosthesis was in the 1930s when there was another attempt at constructing a conduit for urine (5). The first penile prosthesis used for sexual function was attempted in 1936 in Germany by $\mathrm{N}$. A. Bogoras who used rib cartilage as the implant material. While this model, was designed to function as an os penis from animals with less developed erectile tissue, this was a 
novel idea, the cartilage lasted only months before folding on itself or getting reabsorbed by the body (1). This basic operation was expanded upon in 1944 by Dr. Franklin who was the first to publish the details of his operation. Again, the correction was only short lived because the cartilage was not a durable material $(6,7)$. It is widely believed that American physician Dr. Peter Scardino was the first to use a synthetic material but he did not publish his work so the first record of a surgeon using synthetic penile implants belongs to Goodwin and Scott in 1952 (3). The advent of silicone greatly facilitated surgical advancement in the 1960's and 70's. Egyptian plastic surgeon Dr. Beheri was the first to use intracavernosal polyurethane rods inside the tunica albuginea (8-10). These pioneers in penile prosthetics, along with material technology advancements, lead to Dr. Scott's invention.

Dr. Scott's IPP was the first procedure that had inflatable silicone rods, allowing the device to be used when desired and then to be inconspicuous in the detumescent state, unlike semi-rigid models and external prosthesis. Dr. Scott published his procedure in July 1973, describing the two silicone bodies, reservoir and control pump that he had used on his first 5 patients (11). The initial devices were manufactured by American Medical Systems (AMS), a company that Dr. Scott helped to found. AMS (now a division of Boston Scientific Corporation) named the original device the AMS $700^{\circledR}$. In 1983 Mentor (now Coloplast) came on the market, offering a competitor. These two companies continue to be the major suppliers in the U.S. Both companies have improved upon the initial IPP devices $(3,12,13)$.

\section{Innovations in penile prosthetic devices}

The first generation AMS $700^{\circledR}$ predictably had some design problems. The initial devices could not achieve the rigidity that was originally desired. Additionally, the devices were plagued with issues of durability and aneurysms. Over the next decade, minor adjustments including suture-less tubing and caps on the ends of the cylinders improved the durability of the device and reduced operator variability (12). The first big change came in 1986 when AMS started using kink resistant tubing (KRT), further reducing operator error. This development allowed intraoperative measurements because KRT required less precise measurements (3).

Polytetrafluoroethylene (PTFE) sleeves were tried but resulted in unwanted dilation so they were replaced with a multilayer design in 1987 (the AMS $\left.700 \mathrm{CX}^{\circledR}\right)(5,11,13$ ). The AMS $700 \mathrm{CX}^{\circledR}$ was shown to be the superior device with a significant reduction in revision rates (14). Another area of improvement has been the addition of a one-way valve scrotal pump, which improved upon the original pump, prone to accidental inflation (12). Mentor (now Coloplast) also started making improvements to their device, most notably with the invention of Bioflex ${ }^{\circledR}$. Bioflex is a patented polyurethane product that increased tensile strength in the cylinders 7 times and did not allow them to excessively dilate $(15,16)$. The Bioflex ${ }^{\circledR}$ IPP models have shown impressive long-term endurance, with $88 \%$ of devices being reported as entirely operational 10 years post-op $(3,12)$. In 1986, mentor debuted the single cylinder Alpha-1 device which has been shown to have increased device survival and decreased leaking because of the lack of tubing connectors $(17,18)$. In 2000 AMS developed InhibiZone $^{\circledR}$, cylinders impregnated with Minocycline and Rifampin to reduce infections. The new material was found to be very effective, reducing post op infections by $82.4 \%$ $(\mathrm{P}=0.0034)$ at 60 days (19). Two years later Mentor released the $\operatorname{Titan}^{\circledR}$ which boasts a special hydrophilic coating that reduces bacteria's ability to adhere and was able to slowly release any antibiotics chosen by the surgeon. This allowed for more precise antimicrobial coverage. In 2004 it was found that the Titan ${ }^{\circledR}$ cut post op infections in half compared to the Alpha-1 noncoated prosthesis $(1.06 \%$ and $2.07 \%$ infection rates respectively) $(12,20)$.

AMS also started offering different models for different needs including: the AMS $700 \mathrm{CXM}^{\circledR}$ (for men with smaller phalluses), AMS $700 \mathrm{CXR}^{\circledR}$ (for men with fibrosis), and AMS Ultrex ${ }^{\circledR}$, the first attempt to add length and girth. The AMS Ultrex ${ }^{\circledR}$ was ultimately unsuccessful because of problems with durability. The second attempt to add length was the AMS LGX ${ }^{\circledR}$ which offered a $25 \%$ increase in length and girth as it has a bidirectional dacron sleeve. In 1994 AMS tried Ambicor, a two-piece device (minus a reservoir) with the goal of shortening the procedure. The device has largely fallen out of favor, as it cannot achieve the same rigidity as the three-piece inflatable penile implant (12,21-23). The next major change came in 2000 when AMS started using a parylene coating to reduce friction (24).

Another major improvement to the devices has been in surgical technique and technology. As the device has evolved, surgical technique has become more standardized to minimize variability. Both companies have color coded tubing. Additional tools such as Scott hooks, the Furlow insertor, Keith needle and Carrion-Rossello Cavernotomes 
have allowed for easier dilation and insertion, a tricky aspect of the procedure, especially in patients with small phalluses or fibrosis. Dr. Eid introduced the "no touch" technique during placement of the penile implant and this has further driven down infection rates $(3,14,25)$. Traditional reservoirs have been placed into the space of Retzius; however, Perito et al. have pioneered the use of anterior transversalis fascia placement of the reservoir which safer in men with prior pelvic surgeries (15). The superficial reservoirs are more difficult to conceal and can be more problematic. Autoinflation is also a problem attributed to constrictive scar tissue surrounding the reservoir balloon and is reported in $1-3 \%$ of patients $(13,18,26)$. Additionally, there is even a higher rate of auto-inflation with these ectopic placements (13). To combat this problem, the Lockout ${ }^{\circledR}$ valve was unveiled in 2000 by Coloplast. This new valve contains a "poppet" valve that minimizes the amount of fluid exiting when a pressure is applied. This minimizes response to external pressures on the device when the patient does the Valsalva maneuver. AMS debuted a similar valve in 2006 in the scrotal pump $(13,26)$. Even with these improvements, it is important to note that IPP is an advanced procedure and most urologists only do few, if any, per year $(3,27)$.

\section{Current problems and directions}

The IPP has evolved since its inception in 1973, but improvement is needed if IPP is to continue to compete with other ED treatments coming-notably gene therapy, extracorporeal shock wave therapy, and other oral agents (28-30). Approximately 25,000 IPP procedures are performed annually in the U.S. (19,31). Additionally, IPP boasts a consumer satisfaction rate of $90 \%$ or higher, suggesting that there is also a lot of work to be done in terms of awareness $(12,32)$. Phosphodiesterase-5 (PDE-5) inhibitors commercials are now very common. This has propelled ED into conversations making men aware of the possible treatment options. However, IPP manufacturers have not seen this type of marketing boost for many reasons including that the procedure is a onetime thing, with no continuing revenue stream when compared to PDE-5 inhibitors. This creates a potential lack of knowledge about the procedure. Identifying these barriers is the first step to innovation, which these devices desperately need to stay as a reasonable option and compete in the massive market of ED therapy. As it stands, less 5\% of eligible patients with refractory ED elect to undergo
IPP (31). The reasons are varied from cost, to anxiety about surgery, to concerns that it's not "natural". This is a telling figure as ED has known psychological, social, and physical effects on both men and their partners (8). Surgical options currently are the only option for a subset of men with refractory ED. In the near future, this will likely remain the best solution for these men as none of the emerging technologies have been shown to be efficacious in ED attributable to innervation or other causes that leave them refractory to therapy. These novel therapies can; however, be an attractive strategy for men who fail medical therapy and are not surgical candidates or who do not want to go through the procedure.

\section{Patient awareness, selection and preference}

In order for the IPP to compete with current and future ED treatment strategies, there must be better patient awareness and education. It has been shown multiple times that there is a high rate of satisfaction amongst men who have undergone IPP as compared to those utilizing pharmacological and external strategies $(33,34)$. In 2016, a retrospective analysis was performed examining 356 men who had been treated for ED. Researchers used the International Index of Erectile Function (IIEF) and Erectile Dysfunction Inventory of Treatment Satisfaction (EDITS) questionnaires. When compared with other modalities, IPP demonstrated significant improvement when compared to other ED treatments. Patients who had an IPP had IIEF mean scored increase most $(12.4 \pm 1.3)$ compared with tadalafil $5 \mathrm{mg}(6.7 \pm 1.5)(\mathrm{P}<0.01)$, tadalafil $20 \mathrm{mg}$ $(6.2 \pm 1.5)(\mathrm{P}<0.01)$, and intracavernosal injection $(8.4 \pm 3.2)$ $(\mathrm{P}<0.05)(34)$. While the evidence suggests that IPP is a highly safe, well tolerated procedure with high rates of user and partner satisfaction, and low revision rates, less than $5 \%$ of eligible patients opt for IPP and this number is only decreasing. In 2002, 4.6\% of eligible patients underwent IPP placement whereas in 2010 only $2.3 \%$ of eligible patients underwent IPP placement $(\mathrm{P}<0.01)$. This decline was noted amongst all ages, ethnicities, and geographic locations (31). There are many theories for this discrepancy including cost, recovery time, and education.

Eligibility for the device is another issue likely to evolve in the future of IPP, especially in the setting of an aging population living healthier for longer. Interestingly, Lee et al. found that though IPP was overall decreasing, there was a bimodal increase in utilization amongst younger males and those with greater comorbidities. A promising $34 \%$ of 
IPP performed in 2010 were on patients with a predicted 10 -year survival rate of less than $25 \%$ (only $20 \%$ in 2002). The proposed reasoning behind this finding was that these men with coronary artery disease etc., had a higher chance of failing treatment and having contraindications to PDE5 inhibitors (31). The IPP is a great option for patients who are healthy enough for surgery but fail oral and injectable therapy, or are not candidates (as in patients with a neurological etiology of ED or post radical prostatectomy). Additionally, there is evidence that IPP is a reasonable option for healthy older men. A 2009 study followed up with 35 patients who underwent an IPP procedure between 1990 and 2007, all who were 70 years or older at the time. Of the 18 still living, $83 \%$ were either very or somewhat satisfied with $73 \%$ still using their device regularly (35). If IPP is to remain a competitive option in the treatment for $\mathrm{ED}$, this demographic must be targeted with advertising, physician recommendations, and specifically patient education. With an aging population, the push to offer older men IPP comes the issue of funding and Medicare coverage for IPP.

\section{Financial and insurance considerations}

As with most issues in healthcare, treatment of ED has been at the center of heated political and economic debates. In 2003 when Medicare part D was unveiled, it covered PDE-5 inhibitors, an industry with 1-billion-dollar annual revenue. In 2006 however, Congress banned Medicare part D from covering ED drugs (36). In 2014, the Achieving a Better Life Experience Act (ABLE) mandated that medicare would even stop covering vacuum erectile devices (VED), without insurance cost \$100-500 and up (37). A 2016 analysis of over 80 popular insurance plans in the US found that men's sexual health coverage was varied and confusing when compared to female breast reconstruction after mastectomy. While breast reconstruction policies were easily found for $94 \%$ of plans examined, only $39 \%$ of plans covered "advanced" (oral and injectable therapy resistant) ED treatment options (38). Currently IPP is covered by most insurance plans, including Medicare, when considered "medically necessary." While the psychological, relationship and psychical effects of ED are clearly described in the literature, the definition of "medically necessary" could change in the coming years. As it stands now, the fact that IPP is a reimbursable, durable and one-time cost solution to $\mathrm{ED}$ makes the point that the procedure is declining troubling.
In the rapidly changing landscape of medical reimbursement and insurance coverage, the future of IPP may even lie outside of complicated and ever changing insurance plans. There is a large industry for elective, cosmetic plastic surgery. People are willing to pay thousands of dollars for breast implants, Botox ${ }^{\circledR}$ injections, liposuction, and other psychical enhancements. In the US, cosmetic surgery is a lucrative and growing industry. Between 1992 and 2005, the annual volume of plastic surgery increased $725 \%$ and $\$ 10$ billion was spent in 2005 , a number that has sky-rocketed in the 11 years since (39). As it stands now, the IPP device alone without surgery costs between $\$ 10,000$ 20,000 without any insurance coverage. This must be able to compete with the popular sildenafil. It is important to note that the patent for sildenafil will run out in 2019, dramatically lowering prices. The future of IPP may be in increasing advertising and targeting of men willing to pay for this long lasting cure for ED out of pocket through things like financing plans. If IPP is going to become akin to a cosmetic procedure, the device must evolve and improve to be competitive.

\section{Device: mimicking natural erections and simplifying use}

While increased awareness and navigating funding is important for the future of IPP, none of this will work without a constantly improving device. Structural integrity and mimicry of the physiologic erections has been a constant source of problem and innovation since the advent of IPP. In 2016, Scovell et al. set out to compare the ex vivo biomechanical properties of leading AMS (AMS 700 $\mathrm{LGX}^{\circledR}$ in 18 and $21 \mathrm{~cm}$ ) and Coloplast devices $\left(\operatorname{Titan}^{\circledR}\right.$ in 18 and $22 \mathrm{~cm}$ ) in different cylinder sizes. They used axial rigidity as a marker for the forces of penetration and tested it with longitudinal forces. The main outcome measure was how many PSI the device could withhold before bending, compromising rigidity. Load testing was performed evaluating vertical and horizontal rigidity with a modified cantilever test. It was found that Coloplast devices were more resistant to sheering forces in both directions. AMS LGX devices depended more on filling pressures and fully inflated devices fared better (40). While these effects would need to be validated in vivo to correlate with rigidity and durability, the future of IPP must include research like this to further develop the product and mimic a natural erection. Future implants should restore a more physiologic erection with bidirectional expansion and have adequate loading 
similar to a human phallus.

Beyond rigidity, the three-dimensional (3D) shape of penile implants has been questioned in the recent years. In 2013, Hakky et al. set out to create 3D models human cadaveric corpus cavernosum and compare them to two different models of Coloplast Titans ${ }^{\circledR}$. The cadaveric penises were harvested and then modeled in SmoothCast 300Q polyurethane molding. These models were then compared to the Coloplast devices using Leios Mesh software, and GOM Inspect software. The 3D scans demonstrated the mean human corporal radii $1 \mathrm{~mm}$ from the distal tip to be $5.03(3.04-6.42) \mathrm{mm}$, which is an obtuse angle. The silicone tipped Titan penile prosthesis spherical radius at the same level was $3.42 \mathrm{~mm}$ while the tip of the AMS prosthesis had a radius of $3.11 \mathrm{~mm}$. Additionally, it was found that human corpora had a curvilinear trajectory with blunt ends (41). The same group later reported that AMS and Coloplast devices were similar when compared (42). This information can, and should, shape the industry. In the future, as technology improves and becomes more readily available, it is reasonable to try $3 \mathrm{D}$ modeling on individual patients, creating a custom device made for them (much like shoe orthotics). Because of variability and factors such as Peyronie's disease fibrosis, the two corpora in the same man could even be different. Personalized medicine is here and only increasing, and IPP has a great opportunity to improve because of this. Manufacturers should consider $3 \mathrm{D}$ printing and other modalities to customize penile implants to patient's specific anatomy. The device itself can be improved upon with problems ranging from lack of customizability, to procedure time, and lack of significant lengthening abilities.

While there is a myriad of potential areas for improvement in the IPP cylinders, pump, and the reservoir, we are currently using technology from the 1970s era. The paradigm of the inflatable penile implant has evolved for the last 40 years and as all paradigms a shift is inevitable. All three-piece penile implants have reservoirs, which are inherently necessary by design; however, they increase operative time and their correct placement and replacement has caused many a complication. Future penile implants will renounce the reservoir for a much simpler operation. Cycling the IPP pump can become an issue for men, as the average age of a man receiving a penile implant is 61 years old $(15,17)$. Many of these men have diabetes, neuropathy, arthritis and coronary artery disease. The future penile implants need to simplify device use and implement technological advancements for ease of patient use. Although a hydraulic IPP is the gold standard it depends on pressure and valves that can break or leak. Even with very low mechanical malfunction rates, the current climate of wasted resources in patient education of IPP pump is ripe for the evolution of a single-touch operation. Patients and physicians will likely welcome this modification alike. In the era of antimicrobial resistance, all surgical hardware must be constantly evolving to stay one step ahead of resistance and sepsis in patients. Today, bacterial and fungal resistances becoming more of a reality for health care providers, the penile implant of the future should evolve to use newer technology that does not rely on antimicrobials, which are bound to encounter resistances. With the emergence of new surgical technology such as Augmented Reality Assisted Surgery (ARAS) may further educate surgeons and warn of potential dangers along with simplifying the IPP operation (43).

Currently, Le et al. are developing a nickel-titanium shape memory alloy penile implant that is heat activated (44). While this technology is on the horizon it appears to be in the early stages. There are several other promising technologies from biomimicry, to 3D printing, to injectable solutions. What is clear is that the penile implant of the future must be simpler and better mimic the physiologic of the human phallus in both the erect and detumesced state.

\section{Conclusions}

The paradigm of the hydraulic IPP has come a long way since its inception. From decreased malfunction rates, and lower infections, to high rates of patient satisfaction, the one durable treatment for ED still has a lot of potential. To stay relevant and competitive there are many areas that Coloplast, AMS and any future competitors should improve upon. The biggest challenges will be integrating new technology into the devices to allow them to be more customizable and effective. The use of $3 \mathrm{D}$ printing, new biomaterials such as the nickel-titanium alloys are a start. However, the next paradigm shift may be an ED treatment from within the corporal tissue in the form of stem cell therapies, gene therapy, or other forms of regenerative medicine. The IPP has shown durability in a changing landscape of ED treatment but must always be evolving to keep up.

\section{Acknowledgements}

None. 


\section{Footnote}

Conflicts of Interest: The authors have no conflicts of interest to declare.

\section{References}

1. Feldman HA, Goldstein I, Hatzichristou DG, et al. Impotence and its medical and psychosocial correlates: results of the Massachusetts Male Aging Study. J Urol 1994;151:54-61.

2. Jonas $\mathrm{U}$. The history of erectile dysfunction management. Int J Impot Res 2001;13:S3-7.

3. Le B, Burnett AL. Evolution of penile prosthetic devices. Korean J Urol 2015;56:179-86.

4. Small MP. Small-Carrion penile prosthesis. A new implant for management of impotence. Mayo Clin Proc 1976;51:336-8.

5. Gee WF. A history of surgical treatment of impotence. Urology 1975;05:401-5.

6. Raheem AA, Kell P. Patient preference and satisfaction in erectile dysfunction therapy: a comparison of the three phosphodiesterase-5 inhibitors sildenafil, vardenafil and tadalafil. Patient Prefer Adherence 2009;3:99-104.

7. Moncada I, Martinez-Salamanca JI, Allona A, et al. Current role of penile implants for erectile dysfunction. Curr Opin Urol 2004;14:375-80.

8. Fisher WA, Rosen RC, Eardley I, et al. Sexual experience of female partners of men with erectile dysfunction: the female experience of men's attitudes to life events and sexuality (FEMALES) study. J Sex Med 2005;2:675-84.

9. Al-Enezi A, Al-Khadhari S, Al-Shaiji TF. Three-piece Inflatable Penile Prosthesis: Surgical Techniques and Pitfalls. J Surg Tech Case Rep 2011;3:76-83.

10. Molodysky E, Liu SP, Huang SJ, et al. Penile vascular surgery for treating erectile dysfunction: current role and future direction. Arab J Urol 2013;11:254-66.

11. Scott FB, Bradley WE, Timm GW. Management of erectile impotence. Use of implantable inflatable prosthesis. Urology 1973;2:80-2.

12. Henry GD. Historical review of penile prosthesis design and surgical techniques: Part 1 of a three-part review series on penile prosthetic surgery. J Sex Med 2009;6:675-81.

13. Hakky TS, Wang R, Henry GD. The evolution of the inflatable penile prosthetic device and surgical innovations with anatomical considerations. Curr Urol Rep 2014;15:410.

14. Wilson SK, Delk JR 2nd. Historical advances in penile prostheses. Int J Impot Res 2000;12 Suppl 4:S101-7.

15. Merrill DC. Mentor inflatable penile prosthesis. Urology 1983;22:504-5.

16. Hackler RH. Mentor inflatable penile prosthesis: A reliable mechanical device. Urology 1986;28:489-91.

17. Wilson SK, Cleves MA, Delk JR 2nd. Comparison of mechanical reliability of original and enhanced Mentor Alpha I penile prosthesis. J Urol 1999;162:715-8.

18. Wilson SK, Henry GD, Delk JR Jr, et al. The mentor Alpha 1 penile prosthesis with reservoir lock-out valve: effective prevention of auto-inflation with improved capability for ectopic reservoir placement. J Urol 2002;168:1475-8.

19. Carson CC 3rd. Efficacy of antibiotic impregnation of inflatable penile prostheses in decreasing infection in original implants. J Urol 2004;171:1611-4.

20. Wolter CE, Hellstrom WJ. The hydrophilic-coated inflatable penile prosthesis: 1-year experience. J Sex Med 2004;1:221-4.

21. Milbank AJ, Montague DK, Angermeier KW, et al. Mechanical failure of the American Medical Systems Ultrex inflatable penile prosthesis: before and after 1993 structural modification. J Urol 2002;167:2502-6.

22. Daitch JA, Angermeier KW, Lakin MM, et al. Long-term mechanical reliability of AMS 700 series inflatable penile prostheses: comparison of CX/CXM and Ultrex cylinders. J Urol 1997;158:1400-2.

23. Montague DK, Angermeier KW, Lakin MM, et al. AMS 3-piece inflatable penile prosthesis implantation in men with Peyronie's disease: comparison of CX and Ultrex cylinders. J Urol 1996;156:1633-5.

24. Kuyava CC. Parylene-coated components for inflatable penile prosthesis. 2006, Google Patents.

25. Mooreville M, Adrian S, Delk JR, et al. Implantation of inflatable penile prosthesis in patients with severe corporeal fibrosis: introduction of a new penile cavernotome. J Urol 1999;162:2054-7.

26. Abbosh PH, Thom MR, Bullock A. Laparascopic capsulotomy to treat autoinflation of inflatable penile prostheses. J Sex Med 2012;9:1212-5.

27. Tausch TJ, Mauck R, Zhao LC, et al. Penile prosthesis insertion for acute priapism. Urol Clin North Am 2013;40:421-5.

28. Kim JH, Lee HJ, Song YS. Mesenchymal stem cell-based gene therapy for erectile dysfunction. Int J Impot Res 2016;28:81-7.

29. Shen HJ, Zhu GY. Advance of neurogenic erectile dysfunction therapy by stem cells. Fa Yi Xue Za Zhi 
2010;26:206-9.

30. Clavijo RI, Kohn TP, Kohn JR, et al. Effects of LowIntensity Extracorporeal Shockwave Therapy on Erectile Dysfunction: A Systematic Review and Meta-Analysis. J Sex Med 2017;14:27-35.

31. Lee DJ, Najari BB, Davison WL, et al. Trends in the utilization of penile prostheses in the treatment of erectile dysfunction in the United States. J Sex Med 2015;12:1638-45.

32. Deveci S, Martin D, Parker M, et al. Penile length alterations following penile prosthesis surgery. Eur Urol 2007;51:1128-31.

33. Megas G, Papadopoulos G, Stathouros G, et al. Comparison of efficacy and satisfaction profile, between penile prosthesis implantation and oral PDE5 inhibitor tadalafil therapy, in men with nerve-sparing radical prostatectomy erectile dysfunction. BJU Int 2013;112:E169-76.

34. Kucuk EV, Tahra A, Bindayi A, et al. Erectile dysfunction patients are more satisfied with penile prosthesis implantation compared with tadalafil and intracavernosal injection treatments. Andrology 2016;4:952-6.

35. Al-Najar A, Naumann CM, Kaufmann S, et al. Should being aged over 70 years hinder penile prosthesis implantation? BJU Int 2009;104:834-7.

36. Polinski JM, Kesselheim AS. Where cost, medical necessity, and morality meet: should US government insurance programs pay for erectile dysfunction drugs? Clin Pharmacol Ther 2011;89:17-9.

Cite this article as: Rodriguez KM, Kohn TP, Davis AB, Hakky TS. Penile implants: a look into the future. Transl Androl Urol 2017;6(Suppl 5):S860-S866. doi: 10.21037/ tau.2017.05.28
37. Discontinued Coverage of Vacuum Erection Systems (VES) Prosthetic Devices in Accordance with the Achieving a Better Life Experience Act of 2014. Medicare Learning Network 2014. Cited 2017 1/1/17.

38. Le B, McAchran S, Paolone D, et al. Assessing the Variability in Insurance Coverage Transparency for Male Sexual Health Conditions in the United States. Urology 2017;102:126-9.

39. Liu TS, Miller TA. Economic analysis of the future growth of cosmetic surgery procedures. Plast Reconstr Surg 2008;121:404e-12e.

40. Scovell JM, Ge L, Barrera EV, et al. Longitudinal and Horizontal Load Testing of Inflatable Penile Implant Cylinders of Two Manufacturers: An Ex Vivo Demonstration of Inflated Rigidity. J Sex Med 2016;13:1750-7.

41. Hakky TS, Ferguson D, Spiess PE, et al. Threedimensional mapping and comparative analysis of the distal human corpus cavernosum and the inflatable penile prosthesis. Asian J Androl 2013;15:567-70.

42. Hakky TS. 3D Reconstruction of the Corpus Cavernosum with Comparative 3D Analysis of the Titan vs the AMS Inflatable Penile Prosthesis 2014.

43. Dickey RM, Srikishen N, Lipshultz LI, et al. Augmented reality assisted surgery: a urologic training tool. Asian J Androl 2016;18:732-4.

44. Le B, McVary K, McKenna K, et al. A Novel Thermalactivated Shape Memory Penile Prosthesis: Comparative Mechanical Testing. Urology 2017;99:136-41. 